\title{
The Unsupported Crowd: Exclusion of Indian Workers in Amazon Mechanical Turk Communities
}

Kristy Milland

Amazon Mechanical Turk ("mTurk") is an online platform where employers, called requesters, post piecework, and workers, many of whom call themselves "Turkers," complete that work for pay. Turkers collect in online communities, such as forums and Facebook groups, to share information about Turking-information that helps some of them earn a living wage (Martin, Hanrahan, O’Neill, \& Gupta, 2014a). MTurk has been widely adopted and celebrated in academic research, both in computing (see Heer \& Bostock, 2010; and Kittur, Chi, \& Suh, 2008) and social science (Paolacci \& Chandler, 2014; Paolacci, Chandler, \& Ipeirotis, 2010). While early research focused on how to most effectively use mTurk as a resource, in the last few years greater attention has been given to ethical considerations involved in using the platform-how, for example, workers are being used as research subjects and whether their treatment is fair (e.g., Busarovs, 2013; Fort, Adda, \& Cohen, 2011; Gupta, Martin, Hanrahan, \& O’Neill, 2014; Kingsley, Gray, \& Suri, 2014; Martin et al., 2014a;). The makeup of these communitiesand how they include or exclude members based on characteristics such as gender, race, age, or nationality - has not been widely studied, despite a large body of research on inclusion and exclusion in voluntary online communities (e.g., Collier \& Bear, 2012; Forte et al., 2012; Geiger \& Ribes, 2010; Gelley, 2013; Lampe \& Johnston, 2005).

This paper first looks at the academic literature produced on mTurk. This is followed by an explanation of the methods used, both quantitative and qualitative, to better understand the experience of Indian Turkers. Findings are then assessed to illustrate through numbers and narrative what working on mTurk and being part of mTurk communities is like for Indian Turkers. This data indicates that discrimination is common and potentially stands as a barrier to community involvement and increased earnings for workers in India. A case study of an Indian Turker who has been fully able to participate in the broader Turker community and become a leader in worker organizing is presented next, examining his viewpoints on what might be standing between Indian workers and greater inclusion. Lastly, a discussion on directions for 
future work determines what concrete steps might be taken in order to enable Indian Turkers in finding a place in Turker communities and thus be able to access the tools they need to earn a decent income through their work.

\section{Studies of mTurk}

mTurk is a relatively new platform, having only been launched in October 2005 (Amazon Web Services, 2006); but the shortage of research on the lived experience of workers is remarkable-all the more so when one considers the vast, interdisciplinary, and sometimes troubling literature that aims to support requesters in their attempts to make data collection through mTurk faster, cheaper, and more efficient [1].

Morris, Dontcheva, and Gerber (2012), for example, discuss how 'priming' can be used to improve the quality of the results of Turk workers. Priming is a psychological technique used to force subjects into a specific mindset and alter their behaviours. Morris et al. focus on performance gains for the requester; they do not consider at all whether workers want to be manipulated in this fashion. Paolacci et al. (2010) investigate Turker demographics, showing that over one-third hail from India. The authors advise that requesters keep in mind that Turkers do not disappear at year's end as undergraduate students do, and that Turkers have indirect avenues for 'retaliating' against requesters who misrepresent their tasks. Citing prior work, they even write that "in principle requesters can offer workers wages that are disproportionately low [...] with little concern since data quality seems to be not affected by payments" (p. 417). The question of whether it is morally acceptable to do so, however, is not addressed.

Some studies focus on the ethical issues surrounding mTurk, such as low wages, lack of collective bargaining rights and recourse when wronged by an employer, and other serious vulnerabilities (Fort et al., 2011). Other studies argue that because workers themselves seldom claim to be exploited, they are not (e.g., Horton, 2011; Busarovs, 2013). In this category, Busarovs (2013) claims that the "small compensation [offered by] routine crowdsourcing [tasks] is adequate income" for people in "third world countries" (p. 13).

Bederson and Quinn (2011) document the fact that the platform itself does not adequately support the workers, driving them to create their own tools and forums in order to create the shared information resources necessary to make work on mTurk lucrative. As mTurk is a "market for lemons," where the requester cannot judge the quality of the product they will receive before pricing their Human Intelligence Tasks (HIT), this leads to lower pay up front and lower quality results in return. This not only 
drives away 'good' workers, but also decreases the quality of the market itself. What they fail to question is who might be left working on the platform after this process, and how those people so desperate as to work in a market where they are undervalued might be further, and continually, exploited.

In general, existing mTurk-focused studies mainly focus on the platform from the lens of the requester. With a few exceptions (e.g., Martin et al., 2014a; Martin et al., 2014b; Gupta et al., 2014), when they do analyze Turkers it is largely to provide a description of their demographics.

\section{Methods}

This paper is informed by almost ten years of participation and observation as a professional mTurk worker and requester, and as the community manager of Turker Nation-the oldest mTurk worker community. I have spent the last two years as a researcher investigating who works on mTurk, how they work and why they work. The specific findings presented here were arrived at through focused, quantitative investigation of the presence of Indian workers in forums currently available to them. I compare this quantitative data with the number of Indian workers on mTurk. To build upon the numbers with data that represents the experience of Indian Turkers, I also conducted multiple interviews with Manish Bhatia, an exceptional worker from India. Manish provided explicit written consent to be named here, as he has engaged in a fair deal of media outreach and is proud of his leadership within the community. At the time of these interviews, Manish was the only Indian worker, out of the thousands still active on mTurk, who makes his identity known publicly on all of the worker communities that currently exist. Together, this data elucidates the experience of Indian workers and their exclusion from Turker communities.

Manish was recruited in the Turker Nation chat room and interviewed three times, through one main interview, a second follow-up interview a short time later, and a third six months later. These interviews investigated his experience with fellow Turkers regarding community culture, Turker relationships, resource availability and use, and what role communities play as a benefit or detriment to his work. The data was then paired with a document analysis of online forum posts, which further elucidate the experience of Indian Turkers in general, and studies on the demographics of Turker websites. Analyzing this data with a grounded theory approach, I examined both the overarching context of barriers in Turking communities and the example Manish offers as someone who was able to overcome those barriers. 


\section{Findings}

Indian Turkers are often grouped and judged by negative stereotypes, by mTurk itself through usability barriers (Kang, Brown, Dabbish, \& Kiesler, 2014), researchers (Ipeirotis, 2011; Schulze, Seedorf, Geiger, Kaufmann, \& Schader, 2011) and Requesters (Kingsley et al., 2014), and other workers on the forums (Admin, 2013; denzacar, 2010; razorbacks0121, 2012; Tiger, 2010). Studies have been published deriding the quality of Indian Turkers' submissions, such as Schulze et al.'s (2011) paper which states bluntly,

Unfortunately, 102 workers answered at least one of the two "test questions" incorrectly and were excluded from the results. Seventy-nine of the invalid answers could be geo-located to respondents from India.

There is no mention of whether the poor results were mistakes or intentional, just the implication that Indian workers provide low quality results. El Maarry and Balke (2015) describe the difference between honest workers who may not submit correct answers all the time, potentially due to a lack of education or skills, and those who are intentionally cheating the Requester. The former are referred to as "rough diamonds," workers who need and deserve employment, especially those from the "bottom of the income pyramid." To ensure that they are fairly treated, it is important that "rough diamonds" are not simply lumped in with those who commit intentional fraud, and instead these workers are offered tasks that suit their other skills. The authors offer some techniques for weeding out the truly bad apples, which will retain the rough diamonds and allow requesters to leverage their low cost labour. They also do not name the countries from which the poorest quality results came, an indicator that it is not the worker's nationality that is at fault.

Other researchers accuse Indian Turkers of falsifying submitted information, such as in Ipeirotis' (2011) blog post titled "Do Mechanical Turk workers lie about their location?" where he discussed a recent mapping HIT. "The biggest liar? A worker from Chennai, India who reported a zip code corresponding to Tampa in Florida. The IP was a cool 9500 miles away from the reported location!" Whether accurate or not, these papers do not discuss the context of their results, they just further the stereotype that Indian workers are out to cheat the system.

Posts on Turker forums and blogs perpetuate the stereotype of Indian Turker as cheater, liar, or sweatshop slave. An mTurk Forum user named razorbacks0121 (2012) asserts that international workers are scammers, spammers, and cheats, stating that, 
....these Over-See's [sic.] people cannot quit scamming trying to make extra money instead of being honest. ... Watch who all the spamming (on the forums) comes from... you will notice they all come from over see's [1].

A Slashdot forum user named denzacar (2010) posts that,

[o]nly USA-ians and Indians (dots, not feathers) actually get paid. Everyone else gets amazon.com gift certificates. ... As a result from such paying practice most Indian workers on mTurk today are "employed" by sweatshops, churning out mostly worthless HITs. Many of them are probably just copy/paste or random-click scripts [2].

Tiger's (2010) post on mTurk Forum about why so many Requesters have HITs which are qualified for only American Turkers reads,

The truth is: US only because they want proper English. That's the main reason. Read some of the posts in this forum made by Indians and it becomes very clear ... it has nothing to do with discrimination. Stop selfpitying.

The suspension of new registrations by and crackdown against current international workers further solidified the stereotype that Indian Turkers engage in fraud, poor quality work, and cheating (Admin, 2012). Turkers assumed that mTurk was getting rid of these workers because they were not as good as the Americans (Project 2501, 2012). Based on the backlash against them, it is no wonder that Indian Turkers are uncomfortable in joining English-focused Turking communities.

To understand whether or not Indian Turkers are making use of Turking resources, I enumerate their presence on mTurk. Fort et al. (2011) estimate that there are between 15,059 and 42,912 active Turkers. In 2008, Indian Turkers made up only 5 percent of the total worker population (Ross, Irani, Silberman, Zaldivar, \& Tomlinson, 2010), while that number grew through 2010 to 34 percent (Ipeirotis, 2010a) and 2011 to 50 percent (Fort et al, 2011; Schulze et al, 2011). Between the 2011 studies and 2012, no further demographic research was completed; but it is likely that the increase continued until July of 2012 when Amazon disabled the ability for international users to register a new account (Project 2501, 2012), and then began the unfettered suspension of Indian workers. These suspensions were not up for discussion, leading to a slow extinction of Indian Turkers, as evidenced by their decline in numbers to between 33-40 
percent in 2014 (AppAppeal, 2014; Pavlick et al,, 2014). As a result, Indian workers are forced to be more careful than ever about what they say publicly.

Figure 1 - The purple bar indicates US and Indian worker representation on mTurk for comparison. AppAppeal, 2014; S. Giminez, personal communication; Google Analytics, November 18, 2014; L. C. Irani, personal communication; K. Serge, personal communication]

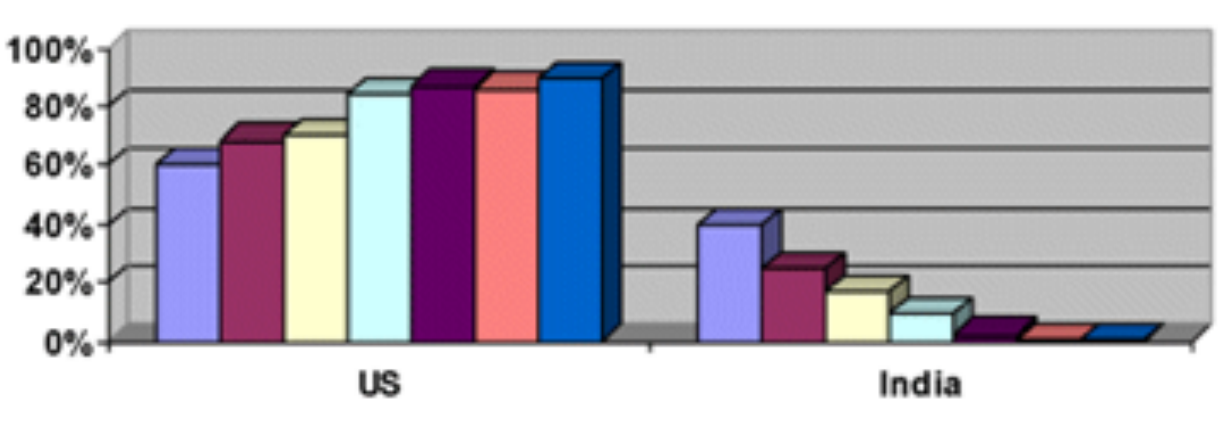

\begin{tabular}{|l|}
\hline$\square$ m Turk.com \\
$\square$ TurkAlert.com \\
$\square$ m TurkForum.com \\
$\square$ Turkopticon.com \\
$\square$ TurkerNation.com \\
$\square$ m TurkList.com \\
$\square$ m TurkGrind.com \\
\hline
\end{tabular}

Yet as Figure 1 shows, they are not using these tools. The two tools with the highest representation stand at less than 25 percent Indian membership each, while the average percentage for the rest is less than 1 percent [3]. This underrepresentation must be explored with causes identified and remedied.

Indian Turkers face many barriers, and they are not using the resources available as a result; therefore, it is imperative to speak to those who are able to leverage these resources in order to learn from their experience. Manish laid out three main obstacles he believes Indian Turkers face. The first is that non-Indian Turkers feel Indian workers accept HITs which are substandard in reward, leading to a reduction in pay across all work. He feels that the stereotype of Indian workers as inferior makes them feel unwelcome on the forums, which is the second obstacle. When they do post, they get replies "shunning" them. His remedy to the problem is that non-Indian Turkers need to allow Indian workers to post about any HIT they need help with, and any Requester they want to learn more about, without being derided for their choice of work. He worries that changing workers' mindsets would be too hard, so he believes that community managers must be more welcoming so members have no choice but to follow in their footsteps. The third obstacle, the language and culture barriers experienced by Indian Turkers causes them to feel shy because they cannot overcome the "communication gap." Thankfully, Manish has an easy solution: instead of creating sites in their 
language, he feels that if Turkers stop pointing out that their language skills are not perfect (Tiger, 2010), they will become comfortable and more active.

Manish has been able to overcome all of these hurdles himself, and he feels that this has not only helped him to earn more, but also to build strong relationships. $\mathrm{He}$ believes that the benefits he receives from his forum memberships are knowledge about tools available, access to tips and tricks, being able to reach Requesters to gain access to work he would not have received on his own, and social support through the friendships he has made. He initially joined a forum because he wanted to become a more efficient Turker; but that led to building camaraderie so strong he sees his closest coworkers as equal to the friends he has offline. Most of all, he feels that he has influenced people's stereotypes about Indian Turkers in a positive way, although he does not think his example has convinced other Indian Turkers to participate more. In the end, he has a sense of pride in the place he has taken amongst his coworkers, and he states, "I think my identity in the communities is just as important to me as the actual Turking I do." He also asserts that community membership is "essential" to a Turker, and that the benefits he sees himself deriving from his community involvement back up that claim.

It is clear from Manish's experience that he deeply believes that his membership on forums is key to his success on mTurk. Despite having to deal with cheques lost in the mail, restrictions disallowing him from doing most HITs, the inability to earn the Masters Qualification until 2014, and all of the regular hurdles Turkers face, he has found a way to make mTurk a lucrative side job [4]. He has also leveraged the social support of his peers through sharing his experience and knowledge abundantly, and by being a friend to them when they need a shoulder to lean on. He is one of the most respected members of the Turker community, and he feels his nationality has never stood in his way. However, he admits that his fluency in English has likely assisted in his assimilation on English-based forums.

Manish has also worked towards change for all Indian Turkers, participating in the Dear Jeff Bezos letter writing campaign via WeAreDynamo.org (2015). In his letter ,he wrote that he was thankful for having the mTurk platform available to work on, because it both gives him something to do when bored and introduced him to "some of the nicest and helpful people." He then detailed his biggest concerns, beginning with the fact that the cheques Amazon mails out rarely ever make it to the Indian workers they are intended for. The second major concern he voiced was that workers are losing their accounts without knowing why, and this lack of transparency must be addressed 
through direct communication between platform staff and the workers. While the second issue has not yet been rectified, Manish and his fellow Indian workers have had their hopes for bank transfers realized, as Amazon announced that Indian workers may now transfer their earnings directly to their bank account. In addition, they received all of the money they were previously owed, a win for Manish and his coworkers (Amazon Mechanical Turk, 2015). Another outcome of Manish's participation in the letter writing campaign was that other Indian workers joined him, writing their own letters and even sharing them publicly on the website. While a preliminary step towards further joining the community publicly, their acceptance by those also in the campaign is a hopeful sign.

\section{Conclusion and Future Work}

Through an investigation of the demographics of mTurk and Turker websites, and interviews with Manish, I have investigated the barriers faced by Indian Turkers and how they can be overcome. We have seen that workers require membership in communities to access the tools and resources necessary to maximize their income on mTurk. It has also been shown that Indian workers are currently unable to leverage that membership and are underrepresented on all of the major Turker websites. Lastly, the ability to overcome this exclusion may be based in breaking down stereotypes and acceptance of all workers regardless of their proficiency in English or work choices on mTurk.

In the spirit of Turkopticon (Irani \& Silberman, 2013), another option would be to create an Indian Turker Bill of Rights. A similar campaign was undertaken on Dynamo (2015), where Turkers collaborated on the Guidelines for Academic Requesters, creating a rulebook for those who use the system so that they know how to ethically interact with the workers. In a similar fashion, input from multiple Indian workers could be gathered via the Dynamo platform, laying out how they feel they should be treated. It could also touch on issues such as what they feel is acceptable pay, the fact they are capable of working on a variety of tasks, and what sort of resources they are seeking access to. The document could continuously be updated with new information, allowing for an evolving text representing the most current state of the workforce. Enforcement could be undertaken by the workers themselves, who might engage in social media shaming of those who do not abide by the conditions as well as traditional media outreach. A coordinated effort would represent to the world that Indian workers are ready to break from the reputation and stereotypes forced on them in the past. It would gather their needs in one place so that other workers, requesters, and Amazon itself 
could learn directly from the source what needs to change. If we work together to create resources that are accessible to Turkers whose first language is not English, and forums that are welcoming to Turkers from around the world, we can change the experience of all mTurk users, workers and requesters alike, for the better.

\section{Endnotes}

1. For example, see Dow, Kulkarni, Klemmer, \& Hartmann, 2012; Downs, Holbrook, Sheng, \& Cranor, 2010; Grier, 2011; Ipeirotis, Provost, \& Wang, 2010b; Jung \& Lease, 2012; Kochhar, Mazzocchi, \& Paritosh, 2010; Mao, Procaccia, \& Chen, 2012; Oleson et al., 2011; Rao, Huang \& Fu, 2013; Snow, O’Connor, Jurafsky, \& $\mathrm{Ng}, 2008)$.

2. See http://mturkforum.com.

3. See http://slashdot.org.

4. See http://turkalert.com and http://mturkforum.com

5. The Masters Qualification is bestowed upon a group of Turkers, curated by Amazon, who are offered to requesters as the best workers on mTurk. The algorithm used to hand it out to workers is closely guarded, and Amazon has never revealed what milestones must be reached to achieve Masters status, nor when it will be handed out again, nor how the status can be maintained.

\section{References}

Admin. (2013, January 17). The reasons why Amazon Mechanical Turk no longer accepts international Turkers. Tips For Requesters On Mechanical Turk. Retrieved August 9, 2018 from http://turkrequesters.blogspot.ca/2013/01/the-reasons-whyamazon-mechanical-turk.html.

Amazon Mechanical Turk. (2015, May 21). Bringing future innovation to Mechanical Turk. Retrieved August 9, 2018 from http://mechanicalturk.typepad.com/blog/2015/05/ bringing-future-innovation-to-mechanical-turk.html. 
Amazon Web Services. (2006). Release: Amazon Mechanical Turk on 2005-10-13. Retrieved August 9, 2018 from https://aws.amazon.com/releasenotes/AmazonMechanical-Turk/66.

AppAppeal. (2014). Amazon Mechanical Turk Alexa Map. Retrieved August 9, 2018 from http://www.appappeal.com/maps/amazon-mechanical-turk.

Bederson, B.B., \& Quinn, A. J. (2011). Web workers unite! Addressing challenges of online laborers. In $\mathrm{CHI}$ '11 Extended Abstracts on Human Factors in Computing Systems (CHI EA '11), 97-106. New York: ACM. doi:10.1145/1979742.1979606

Burrell, J. (2012). Invisible users: Youth in the internet cafés of urban Ghana. Cambridge: MIT Press.

Busarovs, A. (2013). Ethical aspects of crowdsourcing, or is it a modern form of exploitation. International Journal of Economics \& Business Administration, I(1), 3-14.

Collier, B., \& Bear, J. (2012). Conflict, criticism, or confidence: an empirical examination of the gender gap in Wikipedia contributions. In Proceedings of the ACM 2012 Conference on Computer Supported Cooperative Work (CSCW '12), 383-392. New York: ACM. doi:10.1145/2145204.2145265

denzacar. (2010). Inside the Mechanical Turk Sweatshop [Msg 33189968]. Message posted to http://beta.slashdot.org/comments. pl?sid=1748198\&cid=33189968

Dow, S., Kulkarni, A., Klemmer, S., \& Hartmann, B. (2012). Shepherding the crowd yields better work. In Proceedings of the ACM 2012 conference on Computer Supported Cooperative Work (CSCW '12), 1013-1022. New York: ACM. doi:

$10.1145 / 2145204.2145355$

Downs, J. S., Holbrook, M.B., Sheng, S., \& Cranor, L.F. (2010). Are your participants gaming the system?: Screening Mechanical Turk workers. In Proceedings of the SIGCHI Conference on Human Factors in Computing Systems (CHI '10), 2399-2402. New York: ACM. doi:10.1145/1753326.1753688 
Fish, A., \& Srinivasan, R. (2012). Digital labor is the new killer app. New Media \& Society, 14(1), 137-152.

Fort, K., Adda, G., \& Cohen, K. B. (2011). Amazon Mechanical Turk: Gold Mine or Coal Mine? Association for Computational Linguistics, 37(2), 413-420.

Forte, A., Antin, J., Bardzell, S., Honeywell, L., Riedl, J., \& Stierch, S. (2012). Some of all human knowledge: Gender and participation in peer production. In Proceedings of the ACM 2012 conference on Computer Supported Cooperative Work Companion (CSCW '12), 33-36. New York: ACM. doi:10.1145/2141512.2141530

Geiger, R.S., \& Ribes, D. (2010). The work of sustaining order in Wikipedia: The banning of a vandal. In Proceedings of the 2010 ACM Conference on Computer Supported Cooperative Work (CSCW '10), 117-126. New York: ACM. doi: 10.1145/1718918.1718941

Gelley, B. (2013). The dynamics of gatekeeping in online collaborative systems. In Proceedings of the 9th International Symposium on Open Collaboration (WikiSym '13), Article 34. New York: ACM. doi:10.1145/2491055.2491089

Grier, D.A. Error identification and correction in human computation: Lessons from the WPA. (2011). In Proceedings of the 3rd Human Computation Workshop at AAAI (HCOMP '11). Palo Alto, CA: AAAI.

Gupta, N., Martin, D., Hanrahan, B. V., \& O'Neill, J. (2014). Turk-Life in India. In Proceedings of the 18th International Conference on Supporting Group Work (GROUP '14), 1-11. New York: ACM. doi:10.1145/2660398.2660403

Habtegiorgis, A. E., \& Paradies, Y. (2013). Utilising self-report data to measure racial discrimination in the labour market. Australian Journal of Labour Economics, 16(1), 5-41. 
Heer, J., \& Bostock, M. (2010). Crowdsourcing graphical perception: using mechanical turk to assess visualization design. In Proceedings of the SIGCHI Conference on Human Factors in Computing Systems (CHI '10), 203-212. New York: ACM. doi: 10.1145/1753326.1753357

Hellerstein, J., Mclnerney, M., \& Neumark, D. (2011). Neighbors and Co-Workers: The importance of residential labor market networks. Journal of Labor Economics, 29(4), 659-695. doi:10.3386/w14201

Horton, J.J. (2011). The condition of the Turking class: Are online employers fair and honest? Economics Letters 111, 10-12.

Ipeirotis, P.G. (2010a). The New Demographics of Mechanical Turk. A Computer Scientist in a Business School. Retrieved from http://www.behind-the-enemy-lines.com/ 2010/03/new-demographics-of-mechanical-turk.html

Ipeirotis, P.G., Provost, F., \& Wang, J. (2010b). Quality management on Amazon Mechanical Turk. In Proceedings of the ACM SIGKDD Workshop on Human Computation (HCOMP '10), 64-67. New York: ACM. doi:10.1145/1837885.1837906

Ipeirotis, P. (2011). Do Mechanical Turk workers lie about their location? A Computer Scientist in a Business School. Retrieved from http://www.behind-the-enemy-lines.com/ 2011/03/do-mechanical-turk-workers-lie-about.htm

Irani, L.C., \& Silberman, M. S. (2013). Turkopticon: interrupting worker invisibility in amazon mechanical turk. In Proceedings of the SIGCHI Conference on Human Factors in Computing Systems (CHI '13), 611-620. New York: ACM. doi:

$10.1145 / 2470654.2470742$

Jung, H.J., \& Lease, M. (2012). Improving quality of crowdsourced labels via probabilistic matrix factorization. In Proceedings of the 4th Human Computation Workshop at AAAI (HCOMP '12). New York: ACM. 
Kang, R., Brown, S., Dabbish, L., \& Kiesler, S. (2014). Privacy attitudes of Mechanical Turk workers and the US public. In Symposium on Usable Privacy and Security (SOUPS '14). New York: ACM.

Khanna, S., Ratan, A., Davis, J., \& Thies, W. (2010). Evaluating and improving the usability of Mechanical Turk for low-income workers in India. In Proceedings of the First ACM Symposium on Computing for Development (ACM DEV '10). New York: ACM. doi: $10.1145 / 1926180.1926195$

Kingsley, S., Gray, M., \& Suri, S. (2014) Monopsony and the Crowd: Labor for Lemons? In Proceedings of the Internet, Policy \& Politics Conference (IPP2014). London: Oxford University Press.

Kittur, A., Chi, E.H., \& Suh, B. (2008). Crowdsourcing user studies with Mechanical Turk. In Proceedings of the SIGCHI Conference on Human Factors in Computing Systems (CHI '08), 453-456. New York: ACM. doi:10.1145/1357054.1357127

Kochhar, S., Mazzocchi, S., \& Paritosh, P. (2010). The anatomy of a large-scale human computation engine. In Proceedings of the ACM SIGKDD Workshop on Human Computation (HCOMP '10), 10-17. New York: ACM. doi:10.1145/1837885.1837890

Lampe, C., \& Johnston, E. (2005). Follow the (slash) dot: effects of feedback on new members in an online community. In Proceedings of the 2005 international ACM SIGGROUP conference on Supporting group work (GROUP '05), 11-20. New York: ACM. doi:10.1145/1099203.1099206

El Maarry, K., \& Balke, W.T. (2015). Retaining Rough Diamonds: Towards a Fairer Elimination of Low-skilled Workers. In 20th International Conference on Database Systems for Advanced Applications (DASFAA '15).

Madlock, P., \& Booth-Butterfield, M. (2011). The Influence of Relational Maintenance Strategies Among Coworkers. Journal of Business Communication, 49(1), 21-47. doi: $10.1177 / 0021943611425237$ 
Mao, A., Procaccia, A.D., \& Chen, Y. (2013). Better Human Computation Through Principled Voting. In Proceedings of the 27th AAAI Conference on Artificial Intelligence (AAAl '13), 1142-1148. Palo Alto, CA: AAAI.

Martin, D., Hanrahan, B., O'Neill, J., \& Gupta, N. (2014a). Being a Turker. In Proceedings of the ACM Conference on Computer Supported Cooperative Work (CSCW '14). New York: ACM.

Martin, D., O'Neill, J., \& Gupta, N. (2014b). Turk-Life in India. In Proceedings of the ACM International Conference on Supporting Group (GROUP '14). New York: ACM.

Morris, R.R., Dontcheva, M., \& Gerber, E.M. (2012). Priming for Better Performance in Microtask Crowdsourcing Environments. IEEE Internet Computing, 16(5), 13-19. doi: 10.1109/MIC.2012.68

Oleson, D., Sorokin, A., Laughlin, G. P., Hester, V., Le, J., \& Biewald, L. (2011). Programmatic Gold: Targeted and Scalable Quality Assurance in Crowdsourcing. In Proceedings of the 3rd Human Computation Workshop at AAAI (HCOMP '11). Palo Alto, CA: AAAI.

Paolacci, G., Chandler, J., \& Ipeirotis, P. (2010). Running experiments on Amazon Mechanical Turk. Judgment and Decision Making, 5(5), 411-419.

Paolacci, G., \& Chandler, J. (2014). Inside the Turk: Understanding Mechanical Turk as a participant pool. Current Directions in Psychological Science, 23(3), 184-188.

Pavlick, E., Post, M., Irvine, A., Kachaev, D., \& Callison-Burch, C. (2014). The language demographics of Amazon Mechanical Turk. In Transactions of the Association for Computational Linguistics, 2(Feb), 79-92.

Perlow, L, \& Weeks, J. (2002). Who's helping whom? Layers of culture and workplace behavior. Journal of Organizational Behavior, 23, 345-361. 
Project 2501. (2012, July 29). It seems like Mturk is no longer creating new Mturk worker accounts [Msg 1]. Retrieved August 9, 2018 from http://turkernation.com/ showthread.php?12227-It-seems-like-Mturk-is-no-longer-creating-new-Mturk-workeraccounts.

Rao, H., Huang, S. W., \& Fu, W.T. (2013). What will others choose? How a majority vote reward scheme can improve human computation in a spatial location identification task. In Proceedings of the First AAAI Conference on Human Computation and Crowdsourcing (HCOMP '13), 130-137. Palo Alto, CA: AAAI.

razorbacks0121. (2012, October 22). Checks for Indians [Msg 2]. Retrieved August 9 , 2018 from http://mturkforum.com/showthread.php?4435-Checks-for-Indians.

Ross, J., Irani, L.C., Silberman, M.S., Zaldivar, A., \& Tomlinson, B. (2010). Who are the crowdworkers? Shifting demographics in Amazon Mechanical Turk. In CHI '10 Extended Abstracts on Human Factors in Computing Systems (CHI EA '10), 2863-2872. New York: ACM.

Salehi, N., Irani, L. C., Bernstein, M.S., Alkhatib, A., Ogbe, E., Milland, K., \& "Clickhappier". (2015). We Are Dynamo: Overcoming Stalling and Friction in Collective Action for Crowd Workers. In Proceedings of the 33rd Annual ACM Conference on Human Factors in Computing Systems (CHI '15), 1621-1630. New York: ACM. doi: 10.1145/2702123.2702508

Schulze, T., Seedorf, S., Geiger, D., Kaufmann, N., \& Schader, M. (2011). Exploring task properties in crowdsourcing - An empircal study on Mechanical Turk. In Proceedings of the 19th European Conference on Information Systems (ECIS 2011).

Silberman, M.S., Ross, J., Irani, L.C., \& Tomlinson, B. (2010). Sellers' problems in human computation markets. In Proceedings of the ACM SIGKDD Workshop on Human Computation (HCOMP '10), 18-21. New York: ACM. doi:10.1145/1837885.1837891

Sloan, M., Newhouse, R.E., \& Thompson, A. (2013). Counting on Coworkers: Race, social support, and emotional experiences on the job. Social Psychology Quarterly, 76(4), 343-372. doi:10.1177/0190272513504937 
Snow, R., O'Connor, B., Jurafsky, D., \& Ng, A. Y. (2008). Cheap and fast---but is it good? Evaluating non-expert annotations for natural language tasks. In Proceedings of the Conference on Empirical Methods in Natural Language Processing (EMNLP '08), 254-263. Stroudsburg, PA: ACL.

Tiger. (2010, July 26). Payments to indians [Msg 13]. Retrieved August 9, 2018 from http://mturkforum.com/showthread.php?142-Payments-toindians\&p=4865\&viewfull=1\#post 4865 .

WeAreDynamo. (2015). Dear Jeff Bezos. Retrieved August 9, 2018 from http:// wearedynamo.org/dearjeffbezos. 